\title{
Ganho de peso e características de carcaça de bovinos Nelore castrados ou não-castrados terminados em confinamento ${ }^{1}$
}

\author{
Fredson Vieira e Silva ${ }^{2}$, Vicente Ribeiro Rocha Júnior ${ }^{3}$, Ricardo Carvalho de Barros ${ }^{4}$, Daniel \\ Ananias de Assis Pires ${ }^{2}$, Gustavo Chamon de Castro Menezes ${ }^{5}$, Luciana Albuquerque Caldeira ${ }^{6}$
}

${ }^{1}$ Banco do Nordeste/FUNDECI.

2 Curso de Zootecnia/UNIMONTES.

${ }^{3}$ Curso de Zootecnia/UNIMONTES. Bolsista de produtividade da FAPEMIG.

${ }^{4}$ Programa de Pós-graduação em Produção Vegetal no Semi-Árido/UNIMONTES.

5 Zootecnista/UNIMONTES.

6 Programa de Pós-graduação em Ciência de Alimentos/UESB.

RESUMO - Objetivou-se avaliar o ganho de peso e as características de carcaça de bovinos Nelore, castrados ou nãocastrados, terminados em confinamento. Utilizaram-se 36 animais com 24 meses de idade e peso vivo médio inicial de 445,30 (não-castrados) ou 449,57 kg (castrados aos $400 \mathrm{~kg}$ de peso corporal). Os animais foram abatidos aos 50 dias de confinamento, quando atingiram peso vivo médio de 516,30 (não-castrados) e 506,86 kg (castrados). Os animais não-castrados não tiveram aumento no peso vivo final, mas apresentaram maior ganho de peso (1,42 e 1,15 kg). Os pesos de carcaça quente (272,77 e $261,89 \mathrm{~kg})$ e carcaça fria (266,13 e 258,24 kg) não diferiram entre animais não-castrados e castrados. Animais não-castrados apresentaram maior rendimento de carcaça quente (52,88 vs 51,65\% para os não-castrados), todavia, o rendimento de carcaça fria foi similar entre os grupos (51,55 e 52,39\%), em virtude da menor quebra ao resfriamento nos animais castrados (2,43 e 1,40\%). Os pesos absolutos de traseiro especial (133,07 e 131,55 kg), dianteiro (105,65 e 100,09 kg) e ponta-de-agulha (27,41 e 26,60 kg) não diferiram entre animais não-castrados e castrados, mas os pesos relativos de traseiro dos animais castrados foram maiores que dos não-castrados (50,93 vs 50,00\%). O contrafilé dos animais não-castrados foi mais pesado que o dos castrados $(8,41 \mathrm{vs} 7,90 \mathrm{~kg})$. A espessura de gordura $(2,05 \mathrm{vs} 2,21 \mathrm{~mm})$ e a área de olho-de-lombo (66,98 vs $\left.67,48 \mathrm{~cm}^{2}\right)$ não diferiram entre animais não-castrados e castrados. $\mathrm{O}$ pH na carcaça fria em tempos predeterminados até o estabelecimento do rigor mortis também é semelhante entre animais não-castrados e castrados. Animais não-castrados e castrados têm peso de carcaça satisfatório, porém não apresentam acabamento mínimo de $3 \mathrm{~mm}$ de gordura, quando confinados por 50 dias com dieta à base de cana-de-açúcar e concentrado. Para adequação do acabamento, a dieta dos animais deve ser balanceada com maior nível energético.

Palavras-chave: condição sexual, cortes primários, desempenho, rendimento de carcaça

\section{Weight gain and characteristics of carcass of castrated or non-castrated Nellore cattle finished in confinement}

\begin{abstract}
The objective of this work was to evaluate weight gain and carcass characteristics Nellore cattle, castrated or non-castrated, finished in confinement. It was used Thirty six animals with 24 months old and initial 445.30 kg BW (noncastrated) or $449.57 \mathrm{~kg} \mathrm{BW}$ (castrated at $400 \mathrm{~kg} \mathrm{BW}$ ). The animals were slaughtered at 50 days of confinement, when reached $516.30 \mathrm{~kg} \mathrm{BW}$ (non-castrated) and $506.86 \mathrm{~kg} \mathrm{BW}$ (castrated). Non-castrated animals did not have an increase in final BW, but showed higher weight gain (1.42 and $1.15 \mathrm{~kg}$ ). Hot carcass weight (272.77 and $261.89 \mathrm{~kg}$ ) and cold carcass weight (266.13 and $258.24 \mathrm{~kg}$ ) did not differ between non-castrated and castrated animals. Non-castrated animals showed higher hot carcass yield (52.88 vs. 51.65\%) however, cold carcass yield was similar between groups (51.55 and 52.39\%), due to smaller chilling loss in castrated animals (2.43 vs. 1.40\%). Special hindquarter absolute weights (133.07 and $131.55 \mathrm{~kg}$ ), forequarter (105.65 and $100.09 \mathrm{~kg}$ ) and spare ribs $(27.41 \mathrm{and} 26.60 \mathrm{~kg}$ ) did not differ between non-castrated and castrated animals. Forequarter relative values castrated animals were higher than the non-castrated (50.93 versus $50.00 \%)$. The striploin of non-castrated animals was heavier than that of castrated ( $8.41 \mathrm{vs.} 7.90 \mathrm{~kg})$. Fat thickness $(2.05 \mathrm{vs.} 2.21 \mathrm{~mm})$ and loin eye area (66.98 versus $67.48 \mathrm{~cm}^{2}$ ) did not differ between non-castrated and castrated animals. Cold carcass $\mathrm{pH}$ in predetermined time until setting of rigor mortis is also similar between and non-castrated and castrated animals. Non-castrated and castrated animals have satisfactory carcass weight, but have not fat thickness less than $3 \mathrm{~mm}$, when confined for 50 days with diet based on sugar cane and concentrate. To match the fat thickness, the diet of the animals must be balanced with higher energy level.
\end{abstract}

Key Words: carcass yield, performance, primary cuts, sexual condition 


\section{Introdução}

A baixa lucratividade atual da pecuária de corte brasileira estimula a procura por tecnologias para aumento da produtividade dos rebanhos. Neste contexto, a criação de bovinos Nelore (Bos indicus), raça amplamente difundida nas regiões do Brasil, e a utilização de animais não-castrados são alternativas bastante discutidas no cenário nacional, com relatos de que beneficiam o desempenho animal.

Assim, segundo Lima et al. (1998), vários estudos indicam melhor conversão alimentar e maior ganho de peso vivo, em torno de $20 \%$, de bovinos não-castrados em comparação aos castrados, no entanto, apesar de a utilização de animais não-castrados para o abate trazer benefícios para o produtor, em razão de sua maior velocidade de crescimento (Restle et al., 1999), ainda restam dúvidas quanto ao acabamento desses animais (Vaz et al., 2000). Além disso, não existe consenso entre autores, em virtude do elevado número de variáveis que determinam o crescimento e desenvolvimento, quanto à idade e ao peso da castração que resultam em maior ganho de peso e qualidade do produto final.

Portanto, a avaliação do indivíduo com base apenas na conversão e no ganho de peso vivo limita as conclusões obtidas, principalmente por não envolver medidas que determinem a gordura de cobertura e outras características de carcaça importantes na qualidade da carne comercializada. Segundo Luchiari Filho (1995), a avaliação da qualidade ou do rendimento de carcaças é importante para melhoria da eficiência produtiva dos sistemas de produção de bovinos de corte e, atualmente, a classificação e padronização das carcaças permitiria a comercialização mais eficiente.

No Brasil, quase toda a carne consumida não apresenta a qualidade determinada por padrões técnicos definidos por especialistas. Portanto, todos os produtos cárneos originários de bovinos são agrupados em um único grupo usualmente, denominado "carne de boi" ou "carne de vaca" (Coutinho Filho et al., 2006).

O peso inicial dos animais e o tempo de confinamento são fatores determinantes da rentabilidade do sistema de produção. O ganho de peso de animais em confinamento é superior ao obtido com a terminação pasto, no entanto, os custos desse sistema limitam a produção em confinamento, por isso, o confinamento é utilizado como estratégia final de acabamento, em períodos de 40 a 60 dias e com animais com peso inicial de $420 \mathrm{~kg}$ (Nogueira, 2006).

Este trabalho foi realizado para avaliar o ganho de peso e as características de carcaça de bovinos Nelore castrados e não-castrados terminados em confinamento no Norte de Minas Gerais.

\section{Material e Métodos}

O trabalho foi conduzido na Fazenda Experimental de Janaúba, localizada a $14 \mathrm{~km}$ do Campus da Universidade Estadual de Montes Claros (UNIMONTES), no município de Janaúba, Minas Gerais.

Foram utilizados 36 novilhos Nelore tomados ao acaso de um rebanho do município de Janaúba, Minas Gerais. Os animais apresentavam no início do experimento 24 meses de idade e peso médio de 445,30 e 449,57 kg (não-castrados e castrados, respectivamente). No momento da seleção, 18 animais com $400 \mathrm{~kg}$ de peso vivo foram castrados, pelo método de castração cirúrgica, e 18 foram mantidos nãocastrados. Os animais nasceram na mesma época de parição e foram mantidos sempre sob as mesmas condições de manejo e alimentação. O rebanho experimental foi disposto em baias coletivas com área de $10 \mathrm{~m}^{2} /$ animal, parcialmente cobertas, contendo cochos de concreto e bebedouros regulados por torneira-bóia. Os animais passaram por um período de 15 dias de adaptação ao manejo e à dieta, com mais 50 dias de período experimental. As pesagens foram realizadas no início, aos 25 e aos 50 dias de experimento, após 16 horas de jejum de sólidos.

A dieta experimental foi formulada para promover ganho de $1,0 \mathrm{~kg}$ de peso/dia, segundo recomendações de Valadares Filho et al. (2006), e foi fornecida diariamente com excesso de $10 \%$, para permitir sobras. Para atender às necessidades dos animais, as quantidades de alimento foram reajustadas a cada 25 dias, de acordo com a variação de peso e o consumo voluntário.

Os animais foram alimentados à vontade, coletivamente, e os cochos foram completamente limpos toda manhã, no mesmo horário (6 horas), quando as sobras eram pesadas. Em seguida, o volumoso era rigorosamente pesado, assim como o concentrado, e fornecido no cocho, quando volumoso e concentrado eram misturados. À tarde, às 15 horas, o restante da dieta era fornecido.

A dieta utilizada foi a mesma para todo o rebanho experimental. O volumoso, à base de cana-de-açúcar, foi oferecido à vontade e o concentrado $(87,47 \%$ de milho, $10,07 \%$ de farelo de soja, $2,3 \%$ de uréia, $0,26 \%$ de sulfato de amônia, $0,67 \%$ de núcleo mineral e $0,23 \%$ de $\mathrm{NaCl}$ ) foi fornecido em quantidade correspondente a $1,2 \%$ do peso vivo, com base na matéria natural do concentrado.

Todos os animais foram abatidos quando atingiram 50 dias de confinamento, no Frigorífico Independência, localizado na cidade de Janaúba, Minas Gerais, conforme procedimento normal de um frigorífico sob inspeção federal. As carcaças, após pesagem para obtenção do peso da carcaça quente, foram mantidas em câmara de resfriamento 
a aproximadamente $1^{\circ} \mathrm{C}$ por 24 horas. Durante a permanência das carcaças na câmara fria, o pH foi medido no músculo Longissimus dorsi entre a 12르 e 13르 costela 1, 3, 5, 7, 12 e 24 horas após o abate em todos os animais castrados e nãocastrados. Após 24 horas de resfriamento, as carcaças foram novamente pesadas. As meias-carcaças esquerdas resfriadas foram separadas nos cortes primários dianteiro (cinco costelas), ponta-de-agulha e traseiro especial e pesados. Os cortes secundários, contrafilé e picanha, foram retirados da carcaça e pesados, sem passar por desossa e apara. Os valores absolutos dos cortes primários e secundários foram estimados em relação ao peso de carcaça fria. Os rendimentos de carcaça quente e fria foram determinados em relação ao peso vivo obtido na fazenda após jejum de sólidos por 16 horas.

Na meia-carcaça direita, realizou-se um corte perpendicular no músculo Longissimus dorsi, na altura da $12^{\mathrm{a}}$ costela, onde foram avaliadas a espessura de gordura, considerando a média aritmética de três medidas, e a área de olho-de-lombo, conforme metodologia de Aus-Meat Limited (2002). A área de olho-de-lombo também foi estudada em relação a $100 \mathrm{~kg}$ de carcaça fria.

$\mathrm{O}$ escore de gordura e musculosidade foi estimado visualmente na carcaça quente, de forma subjetiva, pelo funcionário da empresa treinado para a avaliação das carcaças. O escore de gordura foi determinado pela escala de classificação de carcaças de 1 a 5 , em que 1 = ausente (0 a $1 \mathrm{~mm}) ; 2$ = escassa $(1 \mathrm{a} 3 \mathrm{~mm}) ; 3=$ mediana $(3 \mathrm{a} 6 \mathrm{~mm}) ; 4=$ uniforme $(6$ a $10 \mathrm{~mm})$ e $5=\operatorname{excessiva~}(>10 \mathrm{~mm})$. A musculosidade foi determinada pela escala de classificação de carcaças de 1 a 3, em que 1 = inferior (subcôncavo e côncavo); 2 = boa (retilíneo); e 3 = excelente (subconvexo e convexo) (Felício, 2003).

O delineamento experimental foi o inteiramente casualizado com dois tratamentos (castrados e não-castrados), de modo que cada tratamento foi composto de 18 repetições. Como as características avaliadas foram classificadas como variáveis quantitativas discretas, testou-se a normalidade e a homogeneidade por meio dos testes de Assimetria e Cochran, respectivamente, de modo que os erros experimentais tiveram distribuição normal de probabilidades e homogeneidade de variâncias, exceto para a variável musculosidade. Aplicou-se o teste Wilcoxon para a variável musculosidade e, para as demais, uma vez confirmada a nãosignificância desses testes, indicando que as pressuposições de normalidade do resíduo e homogeneidade de variâncias foram aceitas, realizou-se análise de variância e compararam-se suas médias pelo teste $\mathrm{F}$ a $5 \%$ de probabilidade (Ribeiro Jr., 2001). O modelo estatístico experimental foi:

$$
\text { Yik }=\mu+\mathrm{Ii}+\text { eik }
$$

em que: Yik = observação $\mathrm{K}$ do animal que recebeu o tratamento $\mathrm{i} ; \mu$ = média geral do experimento; $\mathrm{Ii}=$ efeito do tratamento i; e eik = erro aleatório associado a cada observação.

\section{Resultados e Discussão}

Os animais não-castrados não apresentaram aumento no peso vivo final em jejum (Tabela 1), no entanto, Ribeiro et al. (2004), em pesquisa com bovinos Nelore, observaram maiores pesos de abate e de carcaça em animais não-castrados em comparação aos castrados. Maior peso de abate em animais não-castrados (6,5\%) foi descrito por Vaz et al. (2001), porém em estudo com 112 dias de terminação em confinamento.

Contudo, é importante considerar que atualmente o período utilizado em confinamentos comerciais tem variado de 40 a 60 dias. Segundo Nogueira (2006), em determinado momento, não é possível continuar com os animais em confinamento, pois os custos do ganho de peso se tornam inviáveis, em virtude do acúmulo de gordura, tecido que aumenta a conversão alimentar e onera os custos com alimentação. De acordo com esse autor, animais com $340 \mathrm{~kg}$ de peso vivo confinados até $500 \mathrm{~kg}$ e animais com $420 \mathrm{~kg}$ de peso vivo confinados até $500 \mathrm{~kg}$ tiveram custos de

Tabela 1 - Pesos, ganho de peso e rendimento de carcaça e quebra no resfriamento de bovinos Nelore não-castrados ou castrados

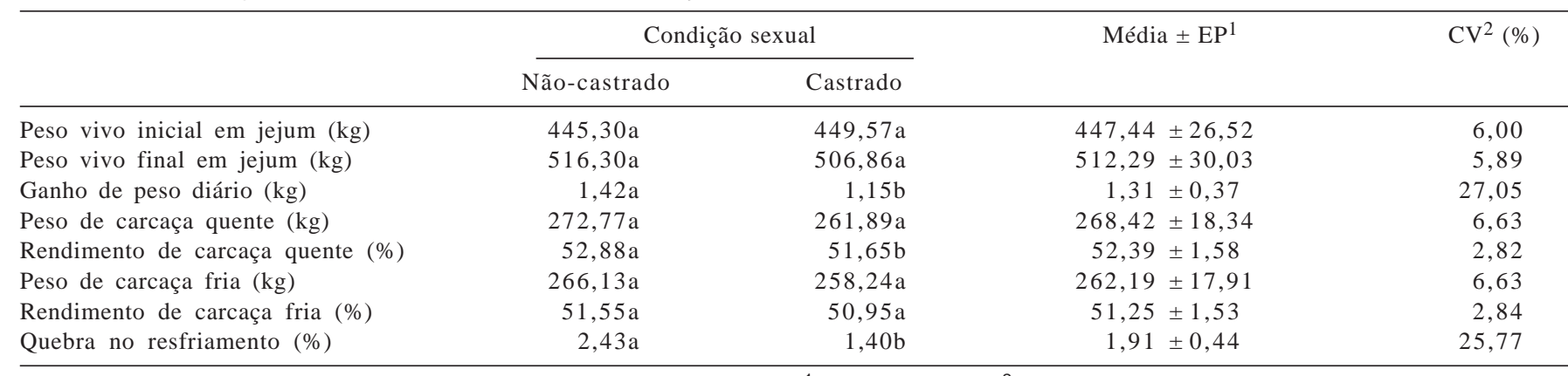

Médias seguidas de letras diferentes na linha diferem $(P<0,05)$ pelo Teste $F ;{ }^{1} E P=$ erro-padrão; ${ }^{2} C V=$ coeficiente de variação. 
alimentação de R\$57,36/@e R\$61,65/@, respectivamente. Entretanto, animais submetidos ao confinamento com 340 e $420 \mathrm{~kg}$ tiveram custo final (boi magro; $200 \mathrm{~km}$ de frete; vermifugação; clostridiose e botulismo; manuseio e distribuição; instalações ealimentação)deR \$61,24/@, R\$54,73/@, respectivamente. A redução de custos esteve relacionada ao menor tempo de confinamento.

Os pesos de carcaça quente e fria não diferiram entre animais não-castrados e castrados. Maior peso de carcaça em animais não-castrados foi observado por Restle et al. (1994), Restle et al. (1996) e Restle e Vaz (1997). Nesta pesquisa, o rendimento de carcaça quente foi maior (2,33\%) nos animais não-castrados $(\mathrm{P}<0,05) \mathrm{e}$, mesmo não havendo diferença $(\mathrm{P}>0,05)$ entre os pesos de carcaça quente $(272,77$ vs $261,89 \mathrm{~kg})$, o aumento (3,99\%) no peso da carcaça dos animais não-castrados resultou em menor rendimento de carcaça quente em comparação aos animais castrados. Os valores são inferiores aos relatados por Costa et al. (2005), que observaram rendimento de carcaça fria de 56,27\% em animais anelorados, mesmo com peso de abate inferior, porém confinados por período mais longo.

$\mathrm{O}$ rendimento de carcaça fria foi semelhante entre os castrados e não-castrados, em decorrênica da menor quebra no resfriamento $(42,39 \%)$ dos animais castrados em relação aos não-castrados. O menor valor na quebra durante o resfriamento da carcaça dos animais castrados - os grupos apresentaram mesmo grau de acabamento (Tabela 3) - pode ser explicado por uma eventual diferença no conteúdo de extrato etéreo e no marmoreio no músculo dos animais, como verificado por Vaz et al. (2001), que observaram menores valores nos animais não-castrados. Outra possível explicação para a menor quebra no resfriamento dos castrados é de que, mesmo que o grau de acabamento não tenha apresentado diferença estatística entre não-castrados e castrados, os castrados apresentaram maior valor numérico na espessura de gordura $(7,24 \%)$.
Para o frigorífico, menor quebra no resfriamento acarretaria maior valor agregado na carcaça comercializada e, para o consumidor, resultaria em melhor qualidade do corte cárneo.

Rendimentos semelhantes entre animais não-castrados e castrados foram também observados por Field (1971) e Morgan et al. (1993). Euclides Filho et al. (2001) relataram mesmo rendimento de carcaça fria entre animais não-castrados e castrados com bovinos Nelore $\times$ Angus e Nelore $\times$ Simental, no entanto, o valor médio neste estudo foi de $57,79 \%$, o que reflete a superioridade dos animais Bos taurus em rendimento de carcaça.

Os pesos do traseiro especial, dianteiro e ponta-deagulha não diferiram significativamente entre as condições sexuais avaliadas (Tabela 2) e apresentaram médias de 132,67, 103,63 e 26,69 kg, respectivamente. Entretanto, Vittori et al. (2006) relataram que animais não-castrados apresentaram maiores pesos de dianteiro, ponta-de-agulha e traseiro especial, refletindo o maior peso vivo de abate e de carcaça quente desse grupo em relação ao dos animais castrados. Neste estudo, os animais castrados apresentaram valores relativos de traseiro maiores que os obtidos nos animais não-castrados $(1,83 \%$; $P<0,05)$. Geralmente, animais nãocastrados apresentam maior proporção de dianteiro e menor de traseiro e ponta-de-agulha, resultado reportado por Restle et al. (2000) em pesquisa com bovinos Charolês, Nelore e seus mestiços, em que o percentual do dianteiro de animais não-castrados foi superior aos dos castrados, que apresentaram maior percentual dos cortes traseiro $(49,4$ vs $48,5 \%)$ e ponta-de-agulha (13,6 vs $12,6 \%$ ). A maior porcentagem de traseiro nos animais castrados não refletiu em aumento do peso da carcaça fria nem de rendimento de carcaça fria, uma vez que dianteiro e ponta-de-agulha foram semelhantes entre animais não-castrados e castrados.

Para o frigorífico interessa, entre outros fatores, carcaças mais pesadas, com bom acabamento, maior rendimento de

Tabela 2 - Peso e rendimento dos cortes comerciais da carcaça de bovinos Nelore não-castrados ou castrados

\begin{tabular}{lcrr}
\hline Variável & \multicolumn{2}{c}{ Condição sexual } & \multirow{2}{*}{ Média $\pm \mathrm{EP}^{1}$} \\
\cline { 2 - 4 } & Não-castrado & Castrado & \\
\hline Traseiro (kg) & $133,07 \mathrm{a}$ & $131,55 \mathrm{a}$ & $132,31 \pm 9,01$ \\
Traseiro (\%) & $50,00 \mathrm{a}$ & $50,93 \mathrm{~b}$ & $50,47 \pm 1,26$ \\
Dianteiro (kg) & $105,65 \mathrm{a}$ & $100,09 \mathrm{a}$ & 2,86 \\
Dianteiro (\%) & $39,37 \mathrm{a}$ & $38,75 \mathrm{a}$ & $102,87 \pm 8,26$ \\
Ponta-de-agulha (kg) & $27,41 \mathrm{a}$ & $26,60 \mathrm{a}$ & $39,06 \pm 1,60$ \\
Ponta-de-agulha (\%) & $10,30 \mathrm{a}$ & $10,32 \mathrm{a}$ & $27,01 \pm 2,50$ \\
Contrafilé (kg) & $8,41 \mathrm{a}$ & $7,90 \mathrm{~b}$ & $10,31 \pm 0,61$ \\
Contrafilé (\%) & $3,13 \mathrm{a}$ & $3,06 \mathrm{a}$ & $8,20 \pm 0,76$ \\
Picanha (kg) & $1,76 \mathrm{a}$ & $1,74 \mathrm{a}$ & $3,10 \pm 0,18$ \\
Picanha (\%) & $0,66 \mathrm{a}$ & $0,67 \mathrm{a}$ & $1,75 \pm 0,19$ \\
\hline
\end{tabular}

Médias seguidas de letras diferentes na linha diferem $(P<0,05)$ pelo teste $F ;{ }^{1} E P=$ erro-padrão; ${ }^{2} C V=$ coeficiente de variação. 
traseiro e de seus cortes básicos aparados, embora essa última característica não signifique vantagens econômicas ao produtor, que recebe basicamente pelo peso (Bonilha et al., 2007) e acabamento da carcaça. Por outro lado, maiores rendimentos refletem em maior eficiência em ganho de carcaça, que tem valor econômico superior ao dos componentes que não fazem parte da carcaça. Todavia, para esta avaliação, deve-se comparar animais com mesma maturidade fisiológica. Assim, segundo Luchiari Filho (1995), a avaliação do rendimento de carcaças é importante para melhoria da eficiência produtiva dos sistemas de produção e, atualmente, a classificação e padronização das carcaças permitiria a comercialização mais eficiente.

Na avaliação do peso de carcaça, é desejável que a proporção de traseiro especial seja superior a $48 \%$, a de dianteiro até 39\% e da ponta-de-agulha até 13\% (Luchiari Filho, 2000). As porcentagens do traseiro (50,47\%), dianteiro (39,06\%) e ponta-de-agulha (10,31\%) dos animais nãocastrados e castrados estão dentro do desejável segundo esse autor. Valores inferiores foram relatados por Vaz e Restle (2005), que, estudando novilhos Hereford, descreveram porcentagens de dianteiro, ponta-de-agulha e traseiro de 36,8; 14,2 e 49,0\%, respectivamente.

As porcentagens dos cortes do traseiro (contrafilé e picanha) não diferiram $(\mathrm{P}>0,05)$ entre animais não-castrados e castrados, no entanto, o contrafilé dos animais nãocastrados foi $0,51 \mathrm{~kg}$ mais pesado $(\mathrm{P}<0,05)$ que o dos castrados. Possivelmente, os não-castrados tiveram maior comprimento do corpo e maior peso do contrafilé. Restle et al. (1994) observaram maiores valores de comprimento de carcaça em animais não-castrados em comparação a animais castrados. De acordo com Domingues (1968), a castração causa ampliação da bacia, fazendo o corpo do animal se apresentar mais curto e cilíndrico.

A espessura de gordura ( $\mathrm{mm})$, o escore de gordura (pontos), a área de olho-de-lombo $\left(\mathrm{cm}^{2}\right)$ e a área de olho-delombo/100 kg ( $\left.\mathrm{cm}^{2}\right)$ não diferiram entre animais não-castrados e castrados (Tabela 3). A tipificação realizada no frigorífico foi eficaz em determinar a espessura de gordura pela avalia- ção subjetiva (escore de gordura), em que os valores médios foram de 2,11 mm para espessura de gordura e 2,17 pontos, que equivale a espessura de gordura de 1 a $3 \mathrm{~mm}$.

Para ser considerada de boa qualidade, uma carcaça deve possuir espessura mínima de gordura de $3 \mathrm{~mm}$ (Luchiari Filho, 2000). A quantidade de gordura é importante, pois, durante o resfriamento, reduz a perda por exsudação e mantém o bom aspecto visual da carcaça (Brondani et al., 2006). A espessura de gordura foi semelhante entre os castrados e não-castrados, no entanto, os animais, de ambos os grupos, apresentaram acabamento abaixo de $3 \mathrm{~mm}$. O aumento do nível energético da dieta no confinamento melhoraria a cobertura de gordura da carcaça de animais não-castrados e castrados. Croiuse et al. (1986), avaliando o músculo Longissimus dorsi de bovinos Angus, relataram que carcaças magras possuíam carne menos macia e mais escura.

Os músculos que amadurecem mais lentamente possibilitam obter o índice mais confiável para avaliação do desenvolvimento muscular dos animais. O músculo Longissimus dorsi é de maturidade tardia e de fácil mensuração, o que o torna preferencial para avaliação do desenvolvimento do tecido muscular (Gesualdi Jr., 2006).

O valor médio da área de olho-de-lombo obtido para não-castrados e castrados foi de $67,18 \mathrm{~cm}^{2}$. Corroborando esse resultado, Vittori et al. (2006) relataram valor médio de área de olho-de-lombo de $66,04 \mathrm{~cm}^{2}$ para animais Nelore não-castrados e castrados. Pádua et al. (2004), no entanto, estudando novilhos Nelore e mestiços de Nelore, observaram valores inferiores (área de olho-de-lombo de $62,85 \mathrm{~cm}^{2}$ para os animais não-castrados e de $58,30 \mathrm{~cm}^{2}$ para os castrados).

A área de olho-de-lombo / 100 kg de carcaça dos animais não-castrados foi de 25,07 e a dos castrados, $26,22 \mathrm{~cm}^{2}$, portanto, não houve diferença $(\mathrm{P}>0,05)$ entre os grupos. De acordo com Luchiari Filho (2000), as medidas de área de olho-de-lombo/100 kg de peso de carcaça são fundamentais para determinação da musculosidade e o valor de $29 \mathrm{~cm}^{2} \mathrm{de}$ área de olho-de-lombo/100 kg de peso de carcaça seria

Tabela 3 - Espessura de gordura, musculosidade e área de olho-de-lombo de carcaça de bovinos Nelore não-castrados ou castrados

\begin{tabular}{lccc}
\hline Variável & \multicolumn{2}{c}{ Condição sexual } & Média $\pm \mathrm{EP}^{1}$ \\
\cline { 2 - 3 } & Não-castrado & Castrado & \\
\hline Espessura de gordura (mm) & $2,05 \mathrm{a}$ & $2,21 \mathrm{a}$ & $2,11 \pm 1,11$ \\
Escore de gordura (pontos) & $2,05 \mathrm{a}$ & $2,36 \mathrm{a}$ & $2,17 \pm 0,51$ \\
Musculosidade (pontos) & $1,95 \mathrm{a}$ & $1,71 \mathrm{~b}$ & $1,86 \pm 0,36$ \\
Área de olho de lombo $\left(\mathrm{cm}^{2}\right)$ & $66,98 \mathrm{a}$ & $67,48 \mathrm{a}$ & $67,18 \pm 8,01$ \\
Área de olho de lombo/100 $\mathrm{kg}\left(\mathrm{cm}^{2}\right)$ & $25,07 \mathrm{a}$ & $26,22 \mathrm{a}$ & 2,91 \\
\hline
\end{tabular}

Médias seguidas por letras diferentes na linha diferem $(P<0,05)$ pelo teste $F ;{ }^{1} E P=$ erro-padrão; ${ }^{2} \mathrm{CV}=$ coeficiente de variação. 
Tabela 4 - pH de carcaça de bovinos Nelore não-castrados ou castrados no rigor post mortem

\begin{tabular}{lccc}
\hline Variável & \multicolumn{2}{c}{ Condição sexual } & Média $\pm \mathrm{EP}^{1}$ \\
\cline { 2 - 3 } & Não-castrado & Castrado & \\
\hline pH 1 hora & $6,99 \mathrm{a}$ & $6,75 \mathrm{a}$ & $6,87 \pm 0,41$ \\
pH 3 horas & $6,26 \mathrm{a}$ & $6,21 \mathrm{a}$ & $6,24 \pm 0,43$ \\
pH 5 horas & $6,12 \mathrm{a}$ & $6,03 \mathrm{a}$ & $6,07 \pm 0,31$ \\
pH 7 horas & $5,86 \mathrm{a}$ & $5,80 \mathrm{a}$ & 5,94 \\
pH 12 horas & $5,70 \mathrm{a}$ & $5,66 \mathrm{a}$ & 5,11 \\
pH 24 horas & $5,70 \mathrm{a}$ & $5,65 \mathrm{a}$ & $5,68 \pm 0,18$ \\
\hline
\end{tabular}

Médias seguidas por letras diferentes na linha diferem $(P<0,05)$ pelo teste $F ;{ }^{1} E P=$ erro-padrão; ${ }^{2} \mathrm{CV}=$ coeficiente de variação.

adequado. Esses resultados indicam que as medidas, tanto dos animais não-castrados quanto dos castrados, estiveram aquém do considerado adequado. A musculosidade dos animais não-castrados e castrados, de acordo com a avaliação subjetiva no frigorífico, foi considerada entre inferior (1) a boa (2). Animais não-castrados apresentaram melhores resultados em comparação aos castrados (1,95 vs 1,71 pontos), no entanto, para o frigorífico, continuaram com mesma classificação. Segundo Camargo et al. (2006), bovinos Nelore não-castrados não apresentam melhor musculosidade em comparação aos castrados.

Os resultados de musculosidade dos animais deste estudo refletem o cotidiano, em que carcaças bovinas de animais Bos indicus geralmente são classificadas como retilíneas, em virtude da menor deposição de músculo em comparação a animais Bos taurus. Assim, os animais Nelore, na maioria das vezes, são abatidos não-castrados para maior deposição de músculo e/ou não-penalização da carcaça, que poderia ser classificada como de musculosidade inferior.

Não houve diferença estatística entre os animais nãocastrados e castrados quanto ao $\mathrm{pH}$ na carcaça fria no post mortem. Entretanto, de acordo com Field (1971), animais não-castrados são mais susceptíveis ao estresse pré-abate, que afeta a deposição de glicogênio no músculo e, posteriormente, o pH da carne. Voisinet et al. (1997), em pesquisa com bovinos Braford, Red Brangus e Simbrah, relataram que animais de temperamento mais excitado têm carne menos macia.

A redução do pH em carcaças favorece a liberação de enzimas proteolíticas, importantes para o aumento da maciez da carne. Além disso, a acidez da carne aumenta significativamente a vida-de-prateleira do produto. De acordo com Vaz \& Restle (2000), variações no pH da carcaça em animais Hereford podem determinar alterações nas características organolépticas e sensoriais da carne. Crouse et al. (1985), trabalhando com bovinos não-castrados e castrados das raças Angus e Simental, verificaram que castrados possuíam carne mais macia que a dos não-castrados. No entanto, como não houve alterações entre não-castrados e castrados nos tempos de 1, 3, 5, 7, 12 e 24 horas após o abate, ocorreu semelhante declínio do $\mathrm{pH}$ em ambas as condições sexuais e que, provavelmente, não ocasionou mudanças nas características organolépticas e sensoriais da carne. Voisinet et al. (1997), no entanto, relatam que animais mais excitáveis têm carne menos macia.

\section{Conclusões}

Quando terminados em confinamento por 50 dias, bovinos Nelore não-castrados apresentam maior ganho de peso, porém mesmo peso de abate de animais castrados. Novilhos Nelore não-castrados são superiores aos castrados quanto ao rendimento de carcaça quente, no entanto, apresentam maiores quebras por exsudação durante o resfriamento, o que resulta em rendimento de carcaça fria similar entre os grupos. Animais não-castrados e castrados têm peso de carcaça satisfatório, porém não apresentam acabamento mínimo de $3 \mathrm{~mm}$ de gordura, quando confinados por 50 dias com peso inicial superior a $400 \mathrm{~kg}$ e com dieta à base de cana-de-açúcar e concentrado (1,2\% do peso vivo). Para adequação do acabamento, a dieta dos animais deve ser balanceada com maior nível energético. Animais Nelore castrados apresentam maior rendimento de traseiro especial e os não-castrados, maior peso de contrafilé. A redução do pH é semelhante entre animais não-castrados e castrados até o estabelecimento do rigor mortis.

\section{Agradecimento}

Ao Banco do Nordeste; à Colonial Agropecuária LTDA; e ao Frigorífico Independência, Unidade de Janaúba, Minas Gerais.

\section{Literatura Citada}

AUS-MEAT [2002]. Limited Australian bovine carcase assessment scheme: beef e veal chiller assessment language. AUS-MEAT Limited. 4p. Disponível em: <http:ausmeat.com.au> Acesso em: 30/3/2004. 
BERG, R.T.; BUTTERFIELD, R.M. New concepts of cattle growth. Sydney: Sydney University Press, 1976. 240p.

BONILHA, S.F.M.; PACKER, I.U.; FIGUEIREDO, L.A. et al. Efeitos da seleção para peso pós-desmame sobre características de carcaça e rendimento de cortes cárneos comerciais de bovinos. Revista Brasileira de Zootecnia, v.36, n.5, p.1275-1281, 2007.

BRONDANI, I.L.; SAMPAIO, A.A.M.; RESTLE, J. et al. Composição física da carcaça e aspectos qualitativos da carne de bovinos de diferentes raças alimentados com diferentes níveis de energia. Revista Brasileira de Zootecnia, v.35, n.5, p.2034-2042, 2006.

CAMARGO, A.M.; RODRIGUES, V.C.; SILVA, B.F.S.L. et al. Características de carcaças de bovinos Nelore comercial nãocastrados e castrados, criados em pastagens e abatidos em duas idades. Boletim da Indústria Animal, v.64, n.1, p.01-07, 2007.

COSTA, M.A.L.; VALADARES FILHO, S.C.; PAULINO, M.F. et al. Desempenho, digestibilidade e características de carcaça de novilhos zebuínos alimentados com dietas contendo diferentes níveis de concentrado. Revista Brasileira de Zootecnia, v.34, n.1, p.268-279, 2005.

COUTINHO FILHO, J.L.V.; PERES, R.M.; JUSTO, C.L. Produção de carne de bovinos contemporâneos, machos e fêmeas, terminados em confinamento. Revista Brasileira de Zootecnia, v.35, n.5, p.2043-2049, 2006.

CROUSE, J.D.; CALKINS, C.R.; SEIDEMAN S.C. The effects of rate of change in body weight on tissue development and meat quality of youthful bulls. Journal of Animal Science, v.63, p.1824-1829, 1986.

CROUSE, J.D.; CROSS, H.R.; SEIDEMAN, S.C. Effects of sex condition, genotype, diet and carcass electrical stimulation on the collagen content and palatability of two bovine muscles. Journal of Animal Science, v.60, p1228-1234, 1985.

DOMINGUES, O. Introdução à Zootecnia. Rio de Janeiro: Serviço de Informação Agrícola, 1968. 392p.

EUCLIDES FILHO, K.; FEIJÓ, G.L.D.; FIGUEIREDO, G.R. Efeito de idade à castração e de grupos genéticos sobre o desempenho em confinamento e características de carcaça. Revista Brasileira de Zootecnia, v.30, n.1, p.71-76, 2001.

FELÍCIO, P.E. [2003]. Tipificação de carcaça bovina. (Material de Aula - FEA/UNICAMP). Disponível em: <http://www.fea. unicamp.br> Acesso em: 10/9/2007.

FIELD, R.A. Effect of castration on meat quality and quantity. Journal of Animal Science, v.32, n.5, p.849-856, 1971.

GESUALDI JR., A.; QUEIROZ, A.C.; RESENDE, F.D. et al. Características de carcaça de bovinos Nelore e Caracu selecionados para peso aos 378 dias de idade, recebendo alimentação restrita ou à vontade. Revista Brasileira de Zootecnia, v.35, n.1, p.131-138, 2006

LIMA, M.L.P.; LEME, P.R.; FREITAS, E.A.B. et al. Aditivos e promotores de crescimento na produção de bovinos de corte. 3.ed. Nova Odessa: Instituto de Zootecnia, 1998. 92p. (Boletim Técnico, 39).

LUCHIARI FILHO, A. A importância da classificação das carcaças bovinas. In: ENCONTRO NACIONAL SOBRE O NOVILHO PRECOCE, 1995, Campinas. Anais... Campinas: 1995. p.125-128.

LUCHIARI FILHO, A. Pecuária da carne bovina. 1.ed. São Paulo: A. Luchiari Filho, 2000. 134p.

MORGAN, J.B.; WHEELER, T.L.; KOOHMARAIE, M. et al. Effect of castration on myofibrillar protein turnover, endogenous proteinase activities, and muscle growth in bovine skeletal muscle. Journal of Animal Science, v.71, n.2, p.408-414, 1993.

NOGUEIRA, M.P. Custos e viabilidade do confinamento frente aos preços baixos. In: ENCONTRO CONFINAMENTO: GESTÃO
TÉCNICA E ECONÔMICA, 1., 2006, Jaboticabal. Palestras... Universidade Estadual Paulista, 2006. p.159-174.

PÁDUA, J.T.; SAINZ, R.D.; PRADO, C.S. et al. Efeitos de grupos genéticos, castração e anabolizantes no desempenho e nas carcaças de bovinos. In: REUNIÃO ANUAL DA SOCIEDADE BRASILEIRA DE ZOOTECNIA, 38., 2001, Piracicaba. Anais... Piracicaba: Sociedade Brasileira de Zootecnia, 2001. p.1518-1519.

RESTLE, J.; GRASSI, C.; FEIJÓ, G.L.D. Características das carcaças e da carne de bovinos não-castrados ou submetidos a duas formas de castração, em condições de pastagem. Revista Brasileira de Zootecnia, v.25, n.2, p.334-344, 1996.

RESTLE, J.; GRASSI, C.; FEIJÓ, G.L.D. Características de carcaça de bovinos de corte não-castrados ou castrados em diferentes idades. Pesquisa Agropecuária Brasileira, v.29, n.10, p.1603-1607, 1994.

RESTLE, J.; VAZ, F.N. Aspectos quantitativos da carcaça de machos Hereford não-castrados ou castrados, abatidos aos quatorze meses. Pesquisa Agropecuária Brasileira, v.32, n.10, p.1091-1095, 1997.

RESTLE, J.; VAZ, F.N.; ALVES FILHO, D.C. Machos não-castrados para a produção de carne. In: RESTLE, J. (Ed.) Confinamento, pastagens e suplementação para produção de bovinos de corte. Santa Maria: Universidade Federal de Santa Maria, 1999. p.215- 231.

RESTLE, J.; GRASSI, C.; FEIJÓ, G.L.D. Características de carcaça de bovinos de corte não-castrados ou castrados em diferentes idades. Pesquisa Agropecuária Brasileira, v.29, n.10, p.1603-1607, 1994.

RESTLE, J.; VAZ, F.N.; FEIJÓ, G.L.D. et al. Características de carcaça de bovinos não-castrados ou castrados de diferentes composições raciais Charolês x Nelore. Revista Brasileira de Zootecnia, v.29, n.5, p.1371-1379, 2000.

RIBEIRO JR., J.I. SAEG - Sistema de análises estatísticas e genéticas. Viçosa, MG: Universidade Federal de Viçosa, 2001. 301p.

RIBEIRO, A.; HERNANDEZ, J.A.; ZANELLA, E.L. et al. Growth and carcass characteristics of pasture fed LHRH immunocastrated, castrated and intact Bos indicus bulls. Meat Science, v.68, n.2, p.285-290, 2004.

VALADARES FILHO, S.C.; PAULINO, P.V.R.; MAGALHÃES, K.A. Exigências nutricionais de zebuínos e Tabelas de composição e alimentos BR-Corte. 1.ed. Viçosa MG: Universidade Federal de Viçosa, 2006. 142p.

VAZ, F.N.; RESTLE, J. Aspectos qualitativos da carcaça e da carne de machos Hereford, não-castrados ou castrados, abatidos aos quatorze meses. Revista Brasileira de Zootecnia, v.29, n.6, p.1894-1901, 2000.

VAZ, F.N.; RESTLE, J. Características de carcaça e da carne de novilhos Hereford terminados em confinamento com diferentes fontes de volumosos. Revista Brasileira de Zootecnia, v.34, n.1, p.230-238, 2005.

VAZ, F.N.; RESTLE, J.; FEIJÓ, G.L.D. Qualidade e composição química da carne de bovinos de corte não-castrados ou castrados de diferentes grupos genéticos Charolês x Nelore. Revista Brasileira de Zootecnia, v.30, n.2, p.518-525, 2001.

VITTORI, A.; QUEIROZ, A.C.; RESENDE, F.D. et al. Características de carcaça de bovinos de diferentes grupos genéticos, castrados e não-castrados, em fase de terminação. Revista Brasileira de Zootecnia, v.35, n.5, p.2085-2092, 2006.

VOISINET, B.D.; GRANDIN, T.; CONNOR, S.F. et al. Bos indicuscross feedlot cattle with excitable temperaments have tougher meat and a higher incidence of borderline dark cutters. Meat Science, v.46, n.4, p.367-377, 1997. 